\title{
Recovery of lithium carbonate by acid digestion and hydrometallurgical processing from mechanically activated lepidolite
}

\author{
Nathália Vieceli $^{\mathrm{a}}{ }$, Carlos A. Nogueira ${ }^{\mathrm{b}}$, Manuel F.C. Pereira ${ }^{\mathrm{c}}$, Fernando O. Durão ${ }^{\mathrm{c}}$, \\ Carlos Guimarães ${ }^{\mathrm{c}}$, Fernanda Margarido ${ }^{\mathrm{a}}$ \\ ${ }^{\text {a }}$ Center for Innovation, Technology and Policy Research $-I N^{+}$, Instituto Superior Técnico, University of Lisbon, 1049-001 Lisboa, Portugal \\ ${ }^{\mathrm{b}}$ LNEG - Laboratório Nacional de Energia e Geologia, I.P., Campus do Lumiar, 1649-038 Lisboa, Portugal \\ c CERENA - Centro de Recursos Naturais e Ambiente, Instituto Superior Técnico, University of Lisbon, 1049-001 Lisboa, Portugal
}

\section{A R T I C L E I N F O}

\section{Keywords:}

Lepidolite

Lithium extraction

Leaching

Precipitation

Purification

\begin{abstract}
A B S T R A C T
Lithium extraction from hard-rock ores has regained importance due to the increased demand for this metal to supply the growing battery market. Therefore, several studies have been focused on the lithium extraction from ores, however, leaching and purification steps are sparsely studied. Thus, the objective of this study was to evaluate the main factors affecting the water leaching step and the subsequent purification operations for lithium recovery from a lepidolite concentrate, which was processed by mechanical activation and sulphuric acid digestion. In the leaching step, among the variables studied, only one, the leaching temperature, showed a significant effect on the lithium extraction, taking into account the range of values tested. Thus, the recommended operating value for the leaching time and the L/S ratio is the minimum, while for the leaching temperature is $50^{\circ} \mathrm{C}$. After optimizing the leaching operation, the purification of the leachate, by neutralization, was thoroughly performed by efficient removal of impurities ( $\mathrm{Fe}, \mathrm{Al}, \mathrm{Mn}$ and $\mathrm{Ca}$ ), allowing to obtain lithium carbonate as final product, as well as other relevant by-products, such as rubidium and potassium alums.
\end{abstract}

\section{Introduction}

Lithium batteries are increasingly used in a large number of applications, from small devices appliances, such as portable electronics, to electric transportation in large scale and stationary grid storage. The secondary battery market is dominated by such batteries, due to their characteristics, such as high energy density, lightweight, long storage life and other superior performance compared to other batteries (Meshram et al., 2016; Julien et al., 2016).

Rechargeable batteries were the largest potential growth area for lithium compounds and their consumption for batteries has increased significantly: in 2016, the global end-use in this market was estimated at $35 \%$, while in 2010 represented $23 \%$ of the global end-use market (Jaskula, 2016). Moreover, between 2014 and 2015, new registrations of electric cars (including both electric and plug-in hybrids) increased by $70 \%$, with over 550,000 vehicles being sold worldwide in 2015 (OECD/IEA, 2016), which has increasingly boosted the demand for this metal.

In the late 1990s, subsurface brines became the main raw material for lithium carbonate production worldwide, due to the lower production costs compared with the mining and processing of hard-rock ores. However, given the growing lithium demand in the past years, hard-rock ores have regained market share (Jaskula, 2016).

After mining, processing of lithium ores involves their comminution, followed by beneficiation using techniques such as flotation, optical sorting, magnetic separation or heavy media separation, in order to upgrade the lithium content and to produce concentrates. Then, these concentrates can be subjected to roasting and leaching to extract lithium into solution (Chagnes and Swiatowska, 2015; Brandt and Haus, 2010; Siame and Pascoe, 2011; Banks et al., 1953; Vieceli et al., 2017a; Menéndez et al., 2004; Munson and Clarke, 1955; Orocobre Limited, 2012).

Lithium ores have been traditionally submitted to a pre-treatment step of calcination or decrepitation followed by acid or alkaline digestion (Meshram et al., 2014; Averill and Olson, 1978; Wietelmann and Bauer, 2000). According to Li et al. (2016), traditional methods for extracting lithium frequently have high costs due to the inefficient exploitation of other metals present in the ores.

Lithium extraction from ores involving a single roasting step using additives has become increasingly important because the time and temperature of the roasting process are reduced. In this context, several studies focused on roasting of lithium ores, with a wide variety of

\footnotetext{
* Corresponding author.

E-mail address: nathalia.vieceli@tecnico.ulisboa.pt (N. Vieceli).
} 